\title{
X. Early Warning of Food Security Crises in Urban areas: the Case of Harare, Zimbabwe, 2007
}

\author{
Molly E. Brown, PhD \\ Christopher C. Funk, PhD
}

\begin{abstract}
In 2007, the citizens of Harare, Zimbabwe began experiencing an intense food security crisis. The crisis, due to a complex mix of poor government policies, high inflation rates and production decline due to drought, resulted in a massive increase in the number of food insecure people in Harare. The international humanitarian aid response to this crisis was largely successful due to the early agreement among donors and humanitarian aid officials as to the size and nature of the problem. Remote sensing enabled an early and decisive movement of resources greatly assisting the delivery of food aid in a timely manner. Remote sensing data gave a clear and compelling assessment of significant crop production shortfalls, and provided donors of humanitarian assistance a single number around which they could come to agreement. This use of remote sensing data typifies how remote sensing may be used in early warning systems in Africa.
\end{abstract}

\section{Introduction}

Africa has experienced rapid urbanization in the past three decades, but unlike many areas of the world, this transition has not been accompanied by strong economic growth. Over the 1970-95 period, the average African country's urban population grew by $5.2 \%$ per annum while its GDP declined by $0.66 \%$ per year (Hicks 2002). In the coming years, supplying the growing number of poor urban residents with safe and affordable food will necessarily strain the food supply and distribution system in Africa, particularly in economies that 
are poorly managed. Zimbabwe, a country currently experiencing quintuple digit inflation, provides a compelling example. This chapter focuses on Zimbabwe's capital city, Harare, and the role that remote sensing has played in identifying and responding to food security crises. In the past few years, Zimbabwe has suffered an economic implosion. Driven largely by the policies of the government, the economic crisis has transformed the country from a net exporter of food to a net importer. This dramatic reduction in average per capita food production, coupled with extremely high rates of inflation, have greatly increased the vulnerability of the residents of Harare to regularly occurring climate-related production declines. Regional food security organizations including the Famine Early Warning Systems Network (FEWS NET) have set up a new food security monitoring program in Harare to monitor the ability of residents to access enough food.

FEWS NET is a program funded by the US Agency for International Development (USAID). It is tasked with monitoring food security in 23 countries in three regions world wide and is composed primarily of local experts who work with specialists in the United States who coordinate their reporting. The organization estimates local food availability, access and utilization with a wide variety of datasets, including remote sensing data and ground measurements of food production as well as a wide range of other indicators meant to measure demand, the ability of a population to purchase food, and other political and economic pressures that may affect the food security of a region (Brown 2008). FEWS NET's objective is to provide early and actionable information that can motivate intervention that will break the link between climate extremes and famine (Davies et al. 1991; Wisner et al. 2004). This chapter describes how remote sensing provided the earliest possible estimate of the national level food security problem which would severely affect residents of Harare, Zimbabwe if no assistance was provided from the humanitarian community, motivating a prompt and effective response.

Because FEWS NET usually focuses on rural areas, its food security monitoring system in Harare is unique. In the urban context, understanding how different economic groups earn income and gain access to food is the basis for evaluating food security. Urban consumers obtain most or all of their food from the market, and thus rely on regional and national food production and distribution systems to ensure there is sufficient food available for purchase. National production deficits can be eliminated with imports from other regions or from outside of the country. If there is insufficient foreign 
currency, lack of political will or lack of sufficient organization to move grain from regions of surplus to regions of deficit, then urban areas are likely to experience rapidly changing food prices, resulting in food insecurity for the most vulnerable groups.

FEWS NET uses a wide variety of remote sensing data products to estimate production at the national and regional level, including earth observations and models. FEWS NET monitors production using remotely sensed vegetation, rainfall, and integrated crop models that measure rainfall variability's impact on yield. It couples these monitoring systems with extensive market price analysis and information on how people in the city gain access to food, through purchase, loan, barter and other means.

In the 2006/07 growing season, farmers in Zimbabwe produced less than expected and significantly less than the long term average due to poor availability of and access to critical inputs such as fertilizers, improved seeds, fuel, electricity, labor and draft power (Figure 1). Land redistribution and inefficient agricultural policies aggravated these constraints. Poor rainfall in the south exacerbated these larger problems, but it was very unclear at the time exactly how much food was produced. It is now thought that the harvest provided 45 percent of Zimbabwe's cereal needs, leaving the country with an import requirement of over $610,000 \mathrm{MT}$ for 2007. Every province in the country faced a cereal deficit, but residents of urban areas had a particularly hard time accessing food because of the extremely high inflation rate which degraded their purchasing power coupled with high international food prices. Remote sensing based production estimates were critical in 2007 to determine the scope of necessary food aid interventions from the international community.

The chapter will first present a description of the food security situation of Harare and the specialized data that FEWS NET collects to determine the needs of its residents. The use of remote sensing in determining the food aid needs in Harare will then be described, along with the technique used to estimate variations in agricultural production. Finally, in the last section a description of food security in urban areas will be presented which explains the key role of remote sensing in providing information about the larger national and regional food production. 


\section{The Emergence of a Crisis}

In the past, Harare and Zimbabwe as a whole coped well with rainfall fluctuations, even though they resulted in large variations in food production due to the predominance of rainfed agriculture. During the 1980s and 1990s, Zimbabwe was food self-sufficient and exported surpluses to its neighbors in southern Africa and beyond, producing significant export income. The country

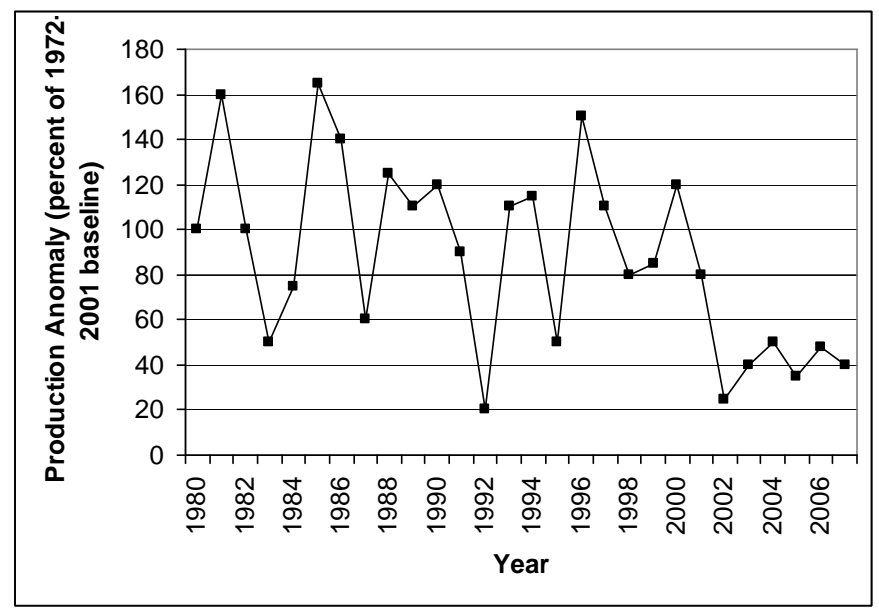

Fig. 1. US Department of Agriculture production statistics for Zimbabwe, expressed as a percentage of the 1972-2001 mean. Note the distinctly lower production from 2001 to 2007 as compared to before 2001 .

survived the droughts of 1982, 1987 and 1992 without substantial disruptions of economic activity (Mudimu 2002). Several interrelated problems are at the basis of its current vulnerability to food insecurity, with drought being one of the least important.

The problems in Zimbabwe began with the implementation of land reform policies in the year 2000 that transferred farms from minority white commercial farmers to majority landless blacks. Although the policies were implemented to improve the equity of land ownership within the country, they have had a severely negative effect on the economy. The land redistribution has meant a complete cessation of organized farming in these formerly commercial farm areas, which used to produce enormous amounts of surplus food every year. Before the land reform, organized white farmers utilized 
sophisticated technology and high levels of fertilizer and seed inputs to produce very high yields. The landless who were resettled on the farms were not provided with the tools, seeds, or know-how needed to tend them properly and have been barely able to grow enough to feed themselves. In 2005, the government exacerbated the economic crisis with an extremely unpopular crackdown on illegal shantytowns in the outskirts of Harare, which led to the demolition of swathes of informal urban settlements. Today Zimbabwe is struggling to cope with a large number of internally displaced people (IDPs), estimated at 570,000 in 2007, according to the Internal Displacement Monitoring Centre.

By the summer of 2007, Zimbabwe's inflation rate was the highest in the world, reaching more than 3,000\% per month. Erratic rainfall in the 2006/7 growing season caused production declines which forced a larger portion of the population to turn to the markets for food, greatly increasing prices in Harare and other urban areas. A meeting was held in March of 2007 in Rome, Italy by the major partners concerned with food security in Zimbabwe (USAID, World Food Program, Southern African Development Council, US Department of Agriculture, the European Commission, European Global Monitoring for Food Security and the European Union's Joint Research Council). The objective of the meeting was to come to a consensus about Zimbabwe's food security situation, about what could be done to assist the country, and to develop a general plan as to how the humanitarian community should proceed. FEWS NET brought to the meeting an estimate of area planted, yield and production for the maize sector for the 2006-7 growing season. These estimates made it clear that crop production was going to fall far below the levels necessary to provide adequate food.

As it became clear that food aid would be needed in 2007, the question was how much assistance was appropriate. Because the national government was unwilling to admit that they had a food security problem or that its policies were the cause, none of the production or planting data coming out of the country in 2007 could be trusted. Although crop areas in the north of the country had a very good rainy season, southern portions had experienced drought during January and February causing crop failures across these areas. Because of the land redistribution, any deficit in production would require that Zimbabwe import grain, but the impact of a government controlled marketing system, the lack of foreign exchange, and a severely constrained private sector due to inflation meant it was uncertain that these imports would be sufficient. Having a reliable, independent estimate of national grain production estimate 
to bring to the Rome meeting was critical to determining the level of support that would be needed by the end of 2007.

\section{Remote Sensing Data to Estimate Maize Production}

FEWS NET routinely uses Normalized Difference Vegetation Index (NDVI) images to identify areas experiencing drought-related reductions in production, as well as poor pasture conditions (FEWS 2000a; Field 1991; Hutchinson 1998), malaria (Hay et al. 1998), epizootic diseases such as Rift Valley Fever (RVF) (Linthicum et al. 1999), and damaging pests such as locusts (Hielkema et al. 1986; Tucker 1985). Although NDVI is useful, estimates of production are usually calculated by FEWS NET as the product of yield, which is modeled with rainfall, and cropped area. While research applications of NDVI to crop yield and production (Bullock 1992; Groten 1993; Rasmussen 1992; Rojas 2007; Unganai and Kogan 1998) have been made, routine quantitative analysis of NDVI is still fairly uncommon. This differs strongly with satellite precipitation (Adler et al. 1994; Arkin et al. 1994; Huffman et al. 1995; Love et al. 2004; Xie and Arkin 1997) which are routinely used to drive numerical models of crop yield reduction (Senay and Verdin 2003). FEWS NET sought a non-rainfall based indicator of production because of huge changes in inputs, area planted and methods used in Zimbabwe in the past few years. Examination of Figure 1 shows a reduction in production since 2002 which confound these models' assumptions of agricultural productivity (Funk and Budde 2008).

In 2006 the Vegetation-Sum metric was developed in analogy to the water requirement satisfaction index (WRSI) water balance model by Chris Funk at the University of California in Santa Barbara, with help from Michael Budde at USGS, in order to improve FEWS NET's ability to predict maize production in Zimbabwe (Funk and Budde 2007). The Vegetation-Sum calculation incorporates a lag that combines delays associated with the temporal sensitivity associated with grain filling and the delayed response of vegetation to rainfall (Funk and Brown 2006; Ji and Peters 2003; Kerr et al. 1989; Potter et al. 1999; Richard and Poccard 1998).

While the WRSI estimates actual evapotranspiration via an extended moisture balance, it has also been shown that MODIS vegetation indices can be a good proxy for actual evapotranspiration (Chong et al. 1993). This suggests that the sum of NDVI increases over the mid-to-late season growing 
period should be a good indicator of crop evapotranspiration. Equation 1 thus summarizes the approach that was taken by Funk and Budde to estimate production using vegetation data.

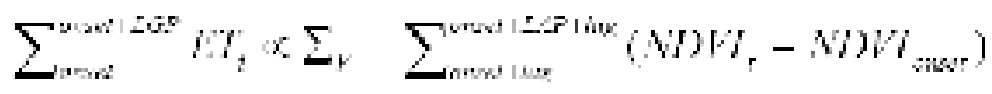

The $\Sigma v$ calculation (Eq. 1) incorporates a lag that combines delays associated with the temporal sensitivity associated with grain filling and the delayed response of vegetation to rainfall (Kerr et al., 1989; Richard \& Poccard, 1998; Potter et al., 1999, Ji \& Peters, 2003; Funk \& Brown, 2005). We also include a length of accumulation period (LAP), which estimates the length of growing period (LGP). LAP determines the length of the window over which the NDVI is summed. NDVI ${ }_{\text {onset }}$ is subtracted from $\Sigma \mathrm{v}$ to remove the pre-onset influences associated with the previous dry and rainy seasons. The dates used in this study for the onset of rains were based on a simple rainfall accounting method defined as the first 10-day period in which at least $25 \mathrm{~mm}$ of rain fell, followed by two 10-day accumulation periods with a total of at least $20 \mathrm{~mm}$ of rain. These onset periods were then linked to the closest 16-day MODIS composite period (Funk and Budde 2008).

While the equation above is physically plausible there are a number of contamination sources that can confound the potential NDVI/ET and crop productivity relationship. Temporally, cloud and moisture contamination can influence the NDVI signal. Vegetation signals from before or after the season contain variations not related to grain filling. Thus an onset-of-rains temporal re-alignment to account for some of these effects was implemented. Finally, spatial filtering was used to minimize the influences of non-agricultural vegetation on the Vegetation-Sum results. Combined with a high-accuracy cropped area map based on 30-m Landsat data, the method provided a way to calculate relative production with high accuracy. Figure 2 shows how variable the NDVI curves that the Vegetation-Sum metric summarizes can be from one year to the next. The $\mathrm{x}$-axis on this plot shows time after the onset of the rainy season. The $y$-axis shows the nationally averaged NDVI minus the NDVI value at onset. Thus the adjusted NDVI is zero at the onset of the rainy season.

A major problem that FEWS NET encountered in implementing this method for the 2007 growing season was the cessation of operational MODIS NDVI data from Collection 4 processing algorithms in January 2007. In order 
to quickly conduct the analysis in March for the April meeting in Rome of key donors, FEWS NET appealed to NASA MODIS processing personnel to conduct a special processing of the MODIS Collection 4 dataset for the region. Since the Collection 4 and the new data from the Collection 5 algorithm are not compatible, FEWS NET would need a complete time series from one or the other in order to conduct its analysis. By communicating the urgency of the situation in Zimbabwe to NASA officials, FEWS NET was able to receive 16 day composites for the four MODIS tiles over the region for the January to March period and the analysis was conducted in time for the key meeting of donors in Rome in the spring of 2007.

The NDVI imagery was used to produce national 2006/07 NDVI averages (Fig. 2), and Vegetation-Sum production estimates. Figure 3 shows a scatterplot of recent PECAD and Vegetation-Sum production anomalies, expressed as a ratio of 2005-06 PECAD production. The 2006/07 VegetationSum estimate was about $35 \%$ below the last season.

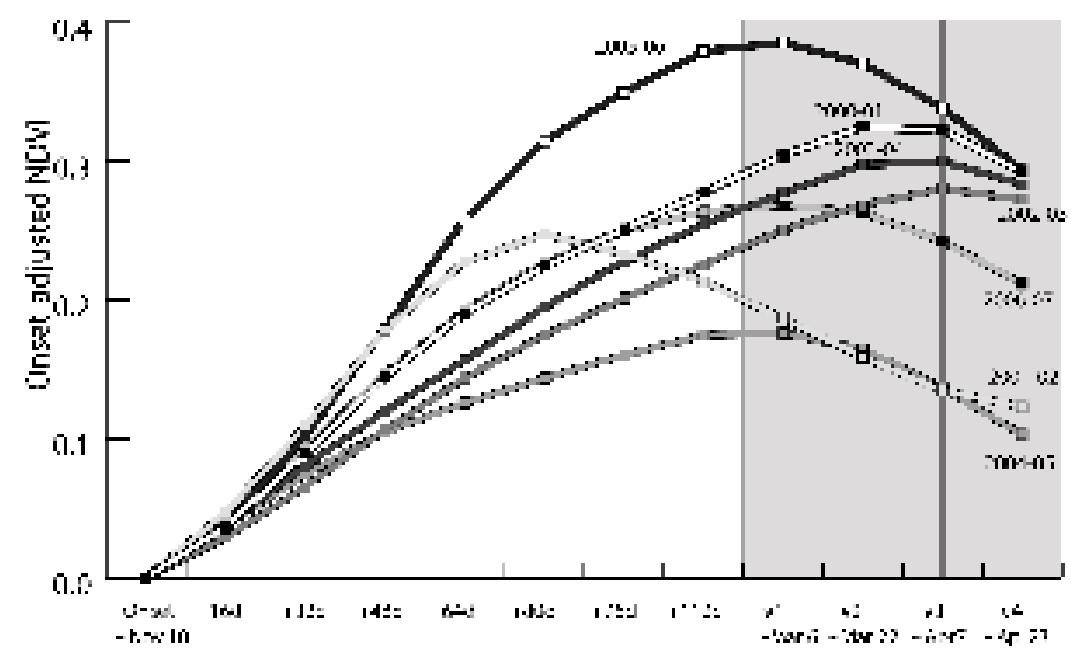

Fig. 2. Composited onset-adjusted MODIS NDVI time series from the onset of rains forward (Funk and Budde, 2007). 
Note that the Vegetation-Sum metric primarily measures yield variations associated with environmental drought. Over the 1999-2007 period production figures and yields are highly correlated $\left(\mathrm{R}^{2}=0.85\right)$, and Vegetation-Sum tracks with both these time-series (Funk and Budde 2007). Variations in area harvested are not captured with this method. In 2006/07 reductions in

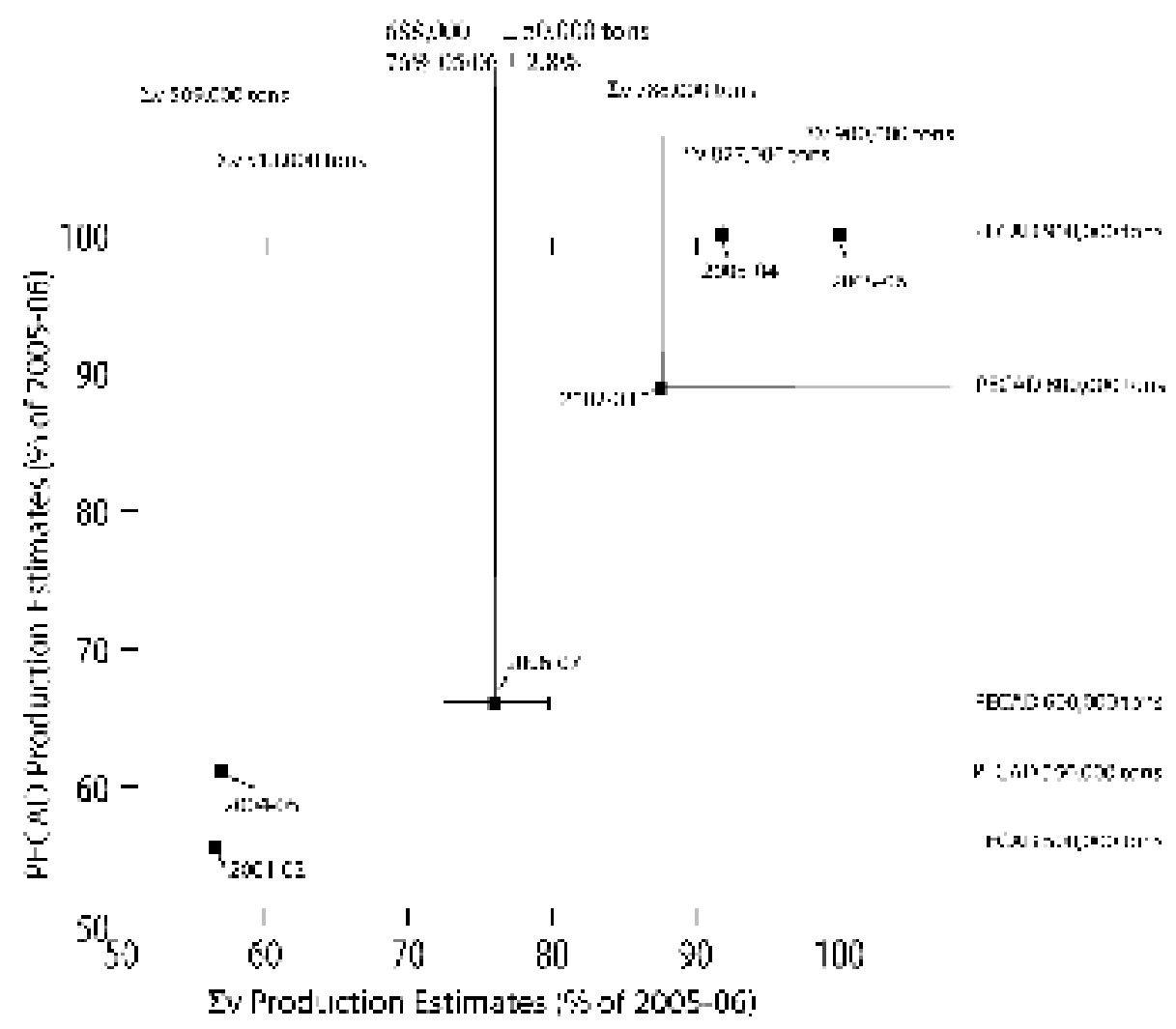

Fig. 3. Scatterplot of six most recent production anomalies calculated from satellite data, expressed a fraction of 2005-06 production. The 2006-07 estimate is also shown, together with brackets indicating \pm 1 standard error $(6 \%)$. In this plot, $\mathrm{Sv}$ denotes the Vegetation-Sum based metric results (Funk and Budde 2008). 
cultivated area were probably responsible for a further $15 \%$ reduction in cereal production (Reynolds 2007).

\section{Measuring Food Security in Harare}

Although the drought in southern Zimbabwe was relatively mild compared to other drought years, the combination of land reform policies and water stress produced dramatic production deficits. People in Harare were particularly vulnerable to food insecurity in 2007 , and thus suffered hunger as a result of this reduction in agricultural production. In order to determine the impact of production deficits documented with remote sensing, FEWS NET conducted food security assessments that analyzed the access that different groups had to food and to cash income in relation to their food and non-food needs. Food security experts tracked changes in access to food and income over time. While the principles underlying the analysis remain the same between urban and rural areas, the details of the analytical approach vary from one context to another.

In a rural setting, it is often most useful to focus on access to food and income for different wealth groups. This is because members of a particular wealth group generally share the same level of food security and a similar limited set of options for obtaining food and income. Members of these groups pursue similar strategies at different times of year. The relative homogeneity of rural livelihoods makes enquiry into sources of food and income the most efficient way to generate a rapid understanding of food security in a rural context (FEWS 2000b).

The same level of homogeneity within wealth groups is generally not found within an urban setting. Here, one source of food - the market - is usually predominant and so the focus of enquiry generally shifts towards questions of cash income and expenditure. In the town, however, there is often a wider range of income sources for any one wealth group, and earnings are also less regular than in the countryside. However, while incomes tend to be heterogeneous in urban settings, patterns of expenditure do not. Poor families tend to spend similar amounts of money on similar things, so that an enquiry into patterns of expenditure is often the most useful approach for establishing an effective baseline for food security monitoring in an urban setting. Since urban economies are primarily market-based, and many of life's essentials, 
often not paid for in a rural setting (i.e. accommodation, water, firewood, etc.), have to be purchased in the town, it is critical for these non-food elements to be incorporated into an urban food security analysis (King et al. 2001).

\section{Income Groups in Harare}

An urban food security monitoring system was set up in Harare in 2001 to determine the ability of residents to access sufficient food. This system monitors a basket of food and non-food items considered essential to live in the city. The purpose of the monitoring system is to track changes and trends over time in relation to the baseline. The monitoring system is focused on providing information on the following on a monthly basis:

- changes in the cost of several expenditure baskets (through market price information),

- changes in formal and informal sector income levels, and

- estimates of the percentage of households falling below the various expenditure thresholds.

The urban monitoring system identified a set of households at different income levels that were vulnerable to changes in food prices and availability and monitored their access to food through time. Although the poorest, middle and highest-income households were identified with annual salary brackets in local currency, the rampant inflation the country has experienced since the assessment made these values meaningless, and therefore they are not reported here. The analysis, documented in a FEWS NET report by King et al 2002 published on the FEWS NET website, describes the Harare monitoring system and each group in detail.

The poorest households had only one income source, either because there was only one able-bodied person of working age in the household, or because of a lack of capital to start up an informal sector activity. Some households in this group are formal sector workers at the lowest salary levels. Others include one household member who is engaged in an informal sector activity such as small-scale vending. A particular problem for those households active in the informal sector is that incomes are irregular and vary daily.

Households in the next income level have one slightly higher formal sector income source (usually from the same categories as the bottom group: factory workers, security guards, shop assistants, etc), sometimes combined with a second income from small-scale vending. Many of the informal sector 
participate in home industries (small tuck shops, carpenters, welders, hair salons and the like) and some vendors also fall into this income range. The highest income level differs from the bottom two by the diversity and number of income sources: private and public sector employees with regular salaries and formal and informal businesses of various types bring this group's income above the national average.

The standard of living of the poorest households is low, and they are forced to largely do without a variety of commodities that are considered to be basic by households that are better off. These include milk, bread, meat, sardines, chicken, rice, margarine, bathing soap, and body lotion. In addition, these households repeatedly stated that they cannot afford health care or transportation. Often they are in debt on their water and electricity bills, paying just what they have to pay to avoid being cut off. Items that are considered to be essential by these households include maize grain, sugar, cooking oil, green vegetables, salt, milling costs, washing soap, vaseline, schooling, accommodation, and second-hand clothes (King et al. 2001).

There is little variation in the diet of the poorest households. They often have only two meals per day and most of their calories come from maize grain, with a small amount from cooking oil, sugar, and, occasionally, dried fish. Vegetables are purchased and add value on the nutritional side, but not very much on the calorie side. At the higher end of the income scale, households can afford a much richer diet, purchasing milk, meat, kapenta, margarine and various other high calorie foods. Absolute expenditure on transport, accommodation, clothing and education also increases as households become richer, as does flexibility to purchase non-essential items.

Where do the poorest households live? Unfortunately for those who seek a simple targeting system, the poorest households can be found throughout the high density and peri-urban areas of Harare. The following are indicators of the presence of these poor households: type of accommodation and rent levels, the availability of services, and whether or not the family has school-aged children who are not attending school. FEWS NET has found that resident association committee members and church groups are able to identify poorer neighborhoods within each residential area and the poorer residents within an area (King et al. 2001). Recent economic upheavals and aggressive government policies against squatters have forced many residents who used to pay rent for accommodation to move to informal dwellings distributed throughout the city, making the poorest even harder to find and more isolated than before. 


\section{Shocks to Food Security in Harare}

During the initial assessment conducted in 2001 to set up the monitoring system, households were surveyed to determine issues that impact food consumption. Households were clear about the types of shocks that cause them problems. Everyone complained about inflation and the fact that residents are constantly battling to keep up with rising prices (Figure 4). Associated with this were specific complaints about devaluation, increases in housing rents and electricity costs, and rising bus fares. Vulnerability to widespread scarcity due to drought is far higher with inflation rampant. Households in both the formal and informal sectors are vulnerable to the illness or death of (or divorce from) the person who earns the main income. If this happens it tends to result in a major drop in the standard of living. AIDS is a particular threat in this regard. Large, unexpected expenditures (such as on funerals or medicines) also cause major problems for poor households, often forcing them into debt (King et al. 2001).

In response to these types of shocks, households engage in a number of coping strategies. Most coping strategies are dependent on a household's own human and material resource base. On the expenditure side, the aim is to minimize spending on and consumption of all items, particularly those that are

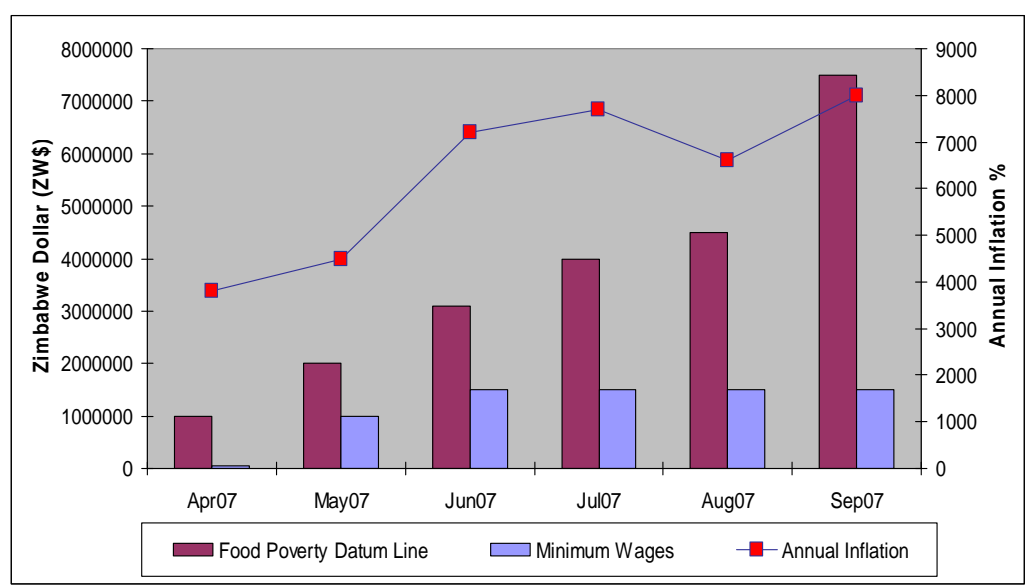

Fig. 4. Annual inflation compared to minimum wage of a low-income earner, indexed on the Food Poverty Line which is calculated using market prices of a minimum basket of necessities. 
considered to be non-essential: purchasing cheaper and poorer quality food; walking or cycling rather than taking the bus; purchasing second-hand rather than new clothes; sending children and other dependants (including terminally ill people) to rural areas to live with relatives; avoiding expenditure by going into debt (on electricity, water and schooling payments); avoiding expenditure by cultivating crops; moving to cheaper accommodation; consuming fewer meals per day. On the income side, the aim is to maximize incomes from all sources: for those working in the formal sector, starting up informal-sector activities to supplement income; sending children out to work; seeking gifts and taking loans from relatives; renting out rooms; selling assets or drawing down savings; and as a last resort, engaging in undesirable, high-risk, or illegal activities such as begging, prostitution, and theft (King et al. 2001).

\section{Food Security Situation in Harare in 2007}

Urban agriculture contributed significantly to cereal needs for urban households, particularly in Harare which is located in a high-potential agriculture area. Unfortunately, urban households had already exhausted food stocks from the spring growing season in September 2006. Since then, the vast majority of the urban population had been dependent on the market for maize and maize meal, with their food access constrained by inflation, low incomes, rising unemployment, price controls and the resultant shortages of food and other basic commodities and exorbitant parallel market food prices. In November 2007, the Zimbabwean economy was stressed even further by foreign exchange shortages. As part of the monitoring that FEWS NET had been conducting in Harare, price trends of selected basic food items were recorded. Many goods had to be purchased on the parallel market, where prices had increased from between 100 and 800 percent during the period of October to December 2007, with little improvement anticipated until government policies change (Figure 5).

While prevailing food insecurity problems had forced poor urban households to reduce or eliminate consumption of meats and other food stuffs considered to be luxury items, the consumption of staple cereals had been conserved to a large extent but only at the expense to other non-food household needs. Coping strategies included reducing expenditures on accommodation, health, education and transportation expenses. The majority 
of people still fortunate to be gainfully employed commuted to and from work on foot or bicycles to cut down on transport costs which were high due to the shortage of fuel. More and more people deferred seeking medical attention from formal health centers and an increasing number turned to cheaper traditional and spiritual healers. To save money, urban poor were relocating to cheaper informal peri-urban settlements. The saved money was directed towards food thereby enabling households to meet their minimum consumption needs. In response, local markets in the poor sections of the urban areas positioned themselves to cater for customers with low and erratic incomes by parceling their food items into very small quantities, tsaona, that are more accessible (FEWS 2008).

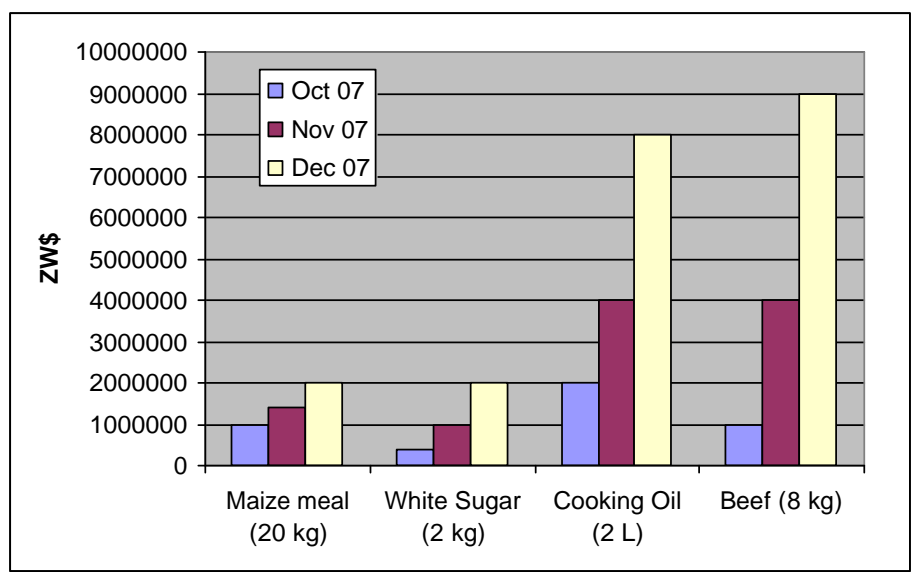

Fig. 5. Trends in parallel market prices of selected food commodities in Harare.

In addition to food shortages, low employment, and high inflation, urban households had to contend with declining level of services like piped water, sewage, electricity, public transportation, and waste collection. While public sector financing declined, over-crowding in peri-urban areas put increasing pressure on a deteriorating infrastructure. Sewage bursts were common in suburbs where the housing density increased significantly. In December 2007, 459 cases of cholera were reported in two high-density suburbs of Harare, attributed by city health officials to the decline in garbage collection, sewer blockages and erratic water supplies. The situation was similar in other urban areas across Zimbabwe. The decline in public services and infrastructure had a 
direct impact on household food security, public health, food utilization and incomes. Continued power cuts had also affected urban household expenditures, with part of a household's meager income now diverted to buying fuel wood for household cooking needs.

\section{Food Availability in 2007}

In April of 2007, the FAO provided funds to Zimbabwe's Ministry of Agriculture to conduct a national multi-stakeholder crop assessment in May 2007. The assessment was required in order to move forward on appeals for assistance for the country. Immediately following the assessment the Government of Zimbabwe declared the drought a disaster and subsequently invited the joint FAO and WFP Crop and Food Supply Assessment mission (CFSAM) to verify the $2006 / 07$ crop production. After its in-country consultations and field work, the mission revised the government's cereal harvest estimates upwards because of improvements in crop performance prospects brought about by better than expected rainfall amounts and distribution towards the end of the 2006/07 rainfall season.

The government's cereal production estimate for 2006/07 agricultural year was the lowest of the previous four years. The estimated production was about 59 percent of the average maize, sorghum and millets (pearl millets and rapoko) harvests for the past five years and 45 percent of the previous year's production estimate of the four staple crops. Taking the government's cereal estimate as the worst-case scenario, combined with carry-over stocks of $153,000 \mathrm{MT}$ of maize, Zimbabwe faced a cereal deficit of 1,050,000 MT in the 2007/08 consumption year. In terms of rainfall performance, the 2005-6 season was a relatively good year, and although there were no reliable estimates of on-farm stocks from that harvest, anecdotal evidence showed that some on farm carry-over stocks existed. The Zimbabwe Vulnerability Assessment Commission of 2006 assessment estimated that about 6 percent of rural households produced in 2006 more than enough to take them to the current harvest (Table 1).

Questions were raised about the Government of Zimbabwe's ability to pay for and import the planned 400,000 MT of maize from Malawi and the remaining 600,000 MT of maize necessary to close the grain consumption gap for the 2007/08 consumption year. A look at the recent historical government 
maize imports and the official foreign currency earnings showed the government's weakness (Figure 6). Available data on exports from the Reserve Bank of Zimbabwe revealed that export earnings had been falling since 1995. In the last half of the 1990s (1995-99) annual average export earnings for Zimbabwe were about US \$2.2 million and averaged about US\$1.85 million from 2001-05. Western countries cut ties with Zimbabwe when the

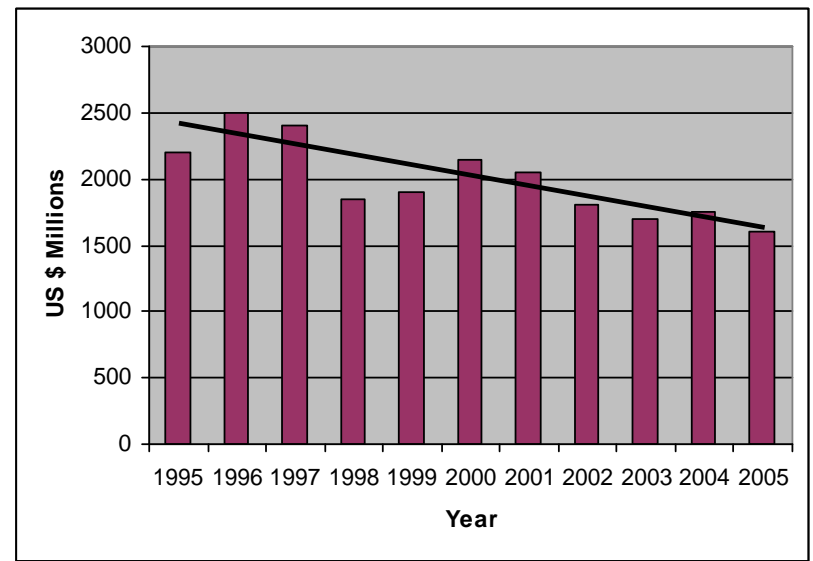

Fig. 6. Government of Zimbabwe's increasing financial stress: a declining annual export earnings in US dollars.

government abandoned the rule of law after launching its chaotic and violent land redistribution program in February 2000. This resulted in Zimbabwe's foreign currency reserves becoming depleted. Despite the worsening foreign currency situation, the government of Zimbabwe managed to respond to perceived maize import requirements in the last five consumption years. In two consumption years, 2002/03 and 2005/06, it managed to import more than $600,000 \mathrm{MT}$ of maize meeting its maize requirement (Table 1).

For Harare residents, meeting immediate food requirements in 2007 had been achieved at the expense of other socio-economic needs. Electricity, fuel, fertilizers, hospital drugs and foreign currency for other economic activities were in critical short supply throughout the previous five years (FEWSNET 2007). In urban areas, water supply was increasingly erratic because of constant pipe and pump breakdowns. Very little infrastructure rehabilitation and development was carried out. Manufacturing firms could not recapitalize enough to reclaim their under-utilized capacity, which is estimated to average 
between 30 to 40 percent. The situation was made worse by the broken economy that limited the availability of employment and other income generating opportunities to the public. Inflation continued to scale new heights with each passing month, and the general increase in the cost of living pushed more and more Zimbabweans deeper into poverty (Figure 6).

\begin{tabular}{|c|c|c|c|c|c|c|}
\hline \multicolumn{7}{|c|}{ Staple Cereals Balance Sheet } \\
\hline Year & 2002 & 2003 & 2004 & 2005 & 2006 & 2007 \\
\hline $\begin{array}{l}\text { Estimated Cereal } \\
\text { Production }\end{array}$ & 641 & 1,172 & 1,882 & 971 & 1,648 & 739 \\
\hline $\begin{array}{l}\text { Estimated } \\
\text { National } \\
\text { Requirement }\end{array}$ & 1,897 & 1,897 & 1,905 & 1,913 & 1,923 & 1,923 \\
\hline Estimated Deficit & $-1,256$ & -725 & -23 & -942 & -275 & $-1,184$ \\
\hline $\begin{array}{l}\text { Percentage Total } \\
\text { Gap }\end{array}$ & -66 & -38 & -1.18 & -49.24 & -14.31 & -61.57 \\
\hline $\begin{array}{l}\text { Percentage Gap } \\
\text { Human Only }\end{array}$ & -58 & -24 & 21.1 & -37.9 & 4.8 & -53.0 \\
\hline
\end{tabular}

Table 1. Main cereal harvest estimates for 2006/07 compared to recent seasons' harvests and their implications for national cereal availability, in thousands.

\section{Conclusions}

Deficits in agricultural production in Zimbabwe during the 2006/7 period were fairly mild if one looks over the past two decades of rainfall variability. The vulnerability of Harare residents had been caused by the large drop in food production and resulting economic upheaval due to government policies, not by variations in rainfall. Had the rainfall deficits that occurred in 2006/7 happened ten years before, little response or no response would have been required. Because of the context in which the deficits occurred, however, remote sensing data was central to the effort to determine early estimates of food production so that plans could be made to provide food aid to the regions that needed it. 
Because of the larger economic crisis in Zimbabwe, variations in national food production remain central to the ability of people in Harare to access food. Remote sensing remains at the center of the effort to detect and motivate early response to food insecurity. MODIS data and the Vegetation Sum analysis that produced early maize production estimates provided a clear and direct way to understand the scope of the problem. Because the situation was a complex economic, political and environmental problem, providing aid on the basis of national food production deficits instead of individual or household need is an expedient and effective way to rapidly provide assistance to regions in turmoil. Remote sensing analysis provided humanitarian decision makers a single number that represented an estimate of food aid needed around which they could come to agreement. This use of remote sensing data typifies how remote sensing is used in early warning systems in Africa.

\section{References}

Adler RF, Huffman GJ and Keehn PR (1994) Global rain estimates from microwaveadjusted geosynchronous IR data. Remote Sensing Reviews, 11: 125-152.

Arkin PA, Joyce R and Janowiak JE (1994) IR Techniques: GOES Precipitation Index. Remote Sensing Reviews, 11: 107-124.

Brown ME (2008) Famine Early Warning Systems and Remote Sensing Data. Springer Verlag, Heildelberg, 402 pp.

Bullock PR (1992) Operational estimates of Western Canadian grain production using NOAA AVHRR LAC data. Canadian Journal of Remote Sensing, 18: 23-28.

Chong DLS, Mougin E and Gastellu-Etchegorry JP (1993) Relating the global vegetation index to net primary productivity and actual evapo transpiration over Africa. International Journal of Remote Sensing, 14: 1517-1546.

Davies SM, Buchanan-Smith M and Lambert R (1991) Early Warning in the Sahel and Horn of Africa: The State of the Art Review of the Literature, Report No.20. Institute of Development Studies, University of Sussex., Brighton, UK, 148 pp.

FEWS (2000a) Annual performance and monitoring report for the Year 2000: FEWS NET, Chemonics International, Washington DC.

FEWS (2000b) Assessing Urban Food Security: Adjusting the FEWS Rural Vulnerability Assessment Framework to Urban Environments, FEWS/ARD, Washington DC. 
FEWS (2008) Famine Early Warning System Network Home Page. USAID FEWS NET.

FEWSNET (2007) Low cereal production, inflation limit food access, US Agency for International Development, Washington DC.

Field JO (1991) Beyond relief: Toward improved management of famine. In: HG Bohle, T Cannon, GI Hugo and FN Ibrahim (Editors), Famine and Food Security in Africa and Asia: Indigenous Response and External Intervention to Avoid Hunger. Verlag, Bayreuth, Germany, pp. 151-166.

Funk C and Budde M (2007) National MODIS NDVI-based production anomaly estimates for Zimbabwe, University of California, Santa Barbara.

Funk CC and Brown ME (2006) Intra-seasonal NDVI change projections in semi-arid Africa. Remote Sensing of Environment, 101: 249-256.

Funk CC and Budde ME (2008) Phenologically-tuned MODIS NDVI-based production anomaly estimates for Zimbabwe. Remote Sensing of Environment, in press.

Groten SME (1993) NDVI-crop monitoring and early yeild assessment of Burkina Faso. Remote Sensing of Environment.

Hicks JF (2002) Sub-Saharan Africa: Enhancing the Productivity of Urban Africa, World Bank, Washington DC.

Hielkema JU, Prince SD and Astle WL (1986) Rainfall and Vegetation Monitoring in the Savanna Zone of the Sudan using the NOAA AVHRR. International Journal of Remote Sensing, 7: 1499-1513.

Huffman GJ, Adler RF, Rudolf B, Schneider U and Keehn PR (1995) Global precipitation estimates based on a technique for combining satellite-based estimates, rain gauge analysis, and NWP model precipitation information. Journal of Climate, 8: 1284-1295.

Hutchinson CF (1998) Social science and remote sensing in famine early warning. In: D Liverman, EF Moran, RR Rindfuss and PC Stern (Editors), People and Pixels: Linking Remote Sensing and Social Science. National Academy Press, Washington DC, pp. 189-196.

Ji L and Peters AJ (2003) Assessing vegetation response to drought in the northern Great Plains using vegetation and drought indices. Remote Sensing of Environment, 87: 85-98.

Kerr YH, Imbernon J, Dedieu G, Hautecoeur O, Lagouarde JP and Seguin B (1989) NOAA AVHRR and Its Uses for Rainfall and Evapotranspiration Monitoring. International Journal of Remote Sensing, 10: 847-854.

King A, Vhurumuku E, Gough N, Nyamutsamba L and Kwenda T (2001) Harare Urban Vulnerability Assessment, FEWS Net and The Consumer Council of Zimbabwe, Harare, Zimbabwe.

Linthicum KJ, Anyamba A, Tucker CJ, Kelley PW, Myers MF and Peters CJ (1999) Climate and Satellite Indicators to Forecast Rift Valley Fever Epidemics in Kenya. Science, 285: 397-400. 
Love TB, Kumar V, Xie P and Thiaw WM (2004) 20-Year Daily Africa Precipitation Climatology using Satellite and Gauge Data, The 84th American Meteorological Society Annual Meeting. AMS, Seattle, WA, pp. 5.4-5.7.

Mudimu G (2002) Zimbabwe Food Security Issues Paper, Forum for Food Security in Southern Africa and the Overseas Development Institute, London.

Potter CS, Klooster S and Brooks V (1999) Interannual variability in terrestrial net primary production: Exploration of trends and controls on regional to global scales. Ecosystems, 2: 36-48.

Rasmussen MS (1992) Assessment of millet yields and production in northern Burkina Faso using integrated NDVI from the AVHRR. International Journal of Remote Sensing, 13: 3431-3442.

Reynolds C (2007) Results from a USDA/USAID crop tour of Zimbabwe.

Richard Y and Poccard I (1998) A Statistical Study of NDVI sensitivity to Seasonal and Interannual Rainfall Variations in Southern Africa. International Journal of Remote Sensing, 19: 2907-2920.

Rojas O (2007) Operational maize yield development and validation based on remote sensing and agro-meteorological data in Kenya. International Journal of Remote Sensing, 28.

Senay GB and Verdin J (2003) Characterization of Yield Reduction in Ethiopia Using a GIS-Based Crop Water Balance Model. Canadian Journal of Remote Sensing, 29: 687-692.

Tucker CJ, Vanpraet, C. L., Sharman, M. J. and van Ittersum, G. (1985) Satellite Remote Sensing of Total Herbaceous Biomass Production in the Senegalese Sahel: 1980-1984. Remote Sensing of Environment, 17: 233-249.

Unganai LS and Kogan FN (1998) Drought Monitoring and Corn Yield Estimation in Southern Africa from AVHRR Data. Remote Sensing of Environment, 63: 219-232.

Wisner B, Blaikie P, Cannon T and Davis I (2004) At Risk: Second Edition. Taylor and Francis Books Ltd, Wiltshire.

Xie P and Arkin PA (1997) Global Precipitation: A 17-year monthly analysis based on gauge observations, satellite estimates, and numerical model outputs. Bulletin American Meteorological Society, 78: 2539-2558. 